\title{
Usefulness of Cerebral Oximetry in TBI by NIRS
}

\author{
Małgorzata Barud ${ }^{1, *(\mathbb{D})}$, Wojciech Dabrowski ${ }^{1}$ (D), Dorota Siwicka-Gieroba ${ }^{1}$ D, Chiara Robba $^{2}$, Magdalena Bielacz $^{3}$ \\ and Rafael Badenes 4 (D)
}

check for updates

Citation: Barud, M.; Dabrowski, W.; Siwicka-Gieroba, D.; Robba, C.; Bielacz, M.; Badenes, R. Usefulness of Cerebral Oximetry in TBI by NIRS. J. Clin. Med. 2021, 10, 2938. https:// doi.org/10.3390/jcm10132938

Academic Editor: Kenji Dohi

Received: 31 May 2021

Accepted: 29 June 2021

Published: 30 June 2021

Publisher's Note: MDPI stays neutral with regard to jurisdictional claims in published maps and institutional affiliations.

Copyright: (c) 2021 by the authors. Licensee MDPI, Basel, Switzerland. This article is an open access article distributed under the terms and conditions of the Creative Commons Attribution (CC BY) license (https:// creativecommons.org/licenses/by/ $4.0 /)$.
1 Department of Anaesthesiology and Intensive Therapy, Medical University of Lublin, 20-954 Lublin, Poland; w.dabrowski5@yahoo.com (W.D.); dsiw@wp.pl (D.S.-G.)

2 Department of Anaesthesia and Intensive Care, Policlinico San Martino, 16100 Genova, Italy; kiarobba@gmail.com

3 Institute of Tourism and Recreation, State Vocational College of Szymon Szymonowicz, 22-400 Zamosc, Poland; magda.bielacz@gmail.com

4 Department of Anaesthesiology and Intensive Care, Hospital Clìnico Universitario de Valencia, University of Valencia, 46010 Valencia, Spain; rafaelbadenes@gmail.com

* Correspondence: gosiekbar@wp.pl

\begin{abstract}
Measurement of cerebral oximetry by near-infrared spectroscopy provides continuous and non-invasive information about the oxygen saturation of haemoglobin in the central nervous system. This is especially important in the case of patients with traumatic brain injuries. Monitoring of cerebral oximetry in these patients could allow for the diagnosis of inadequate cerebral oxygenation caused by disturbances in cerebral blood flow. It could enable identification of episodes of hypoxia and cerebral ischemia. Continuous bedside measurement could facilitate the rapid diagnosis of intracranial bleeding or cerebrovascular autoregulation disorders and accelerate the implementation of treatment. However, it should be remembered that the method of monitoring cerebral oximetry by means of near-infrared spectroscopy also has its numerous limitations, resulting mainly from its physical properties. This paper summarizes the usefulness of monitoring cerebral oximetry by near-infrared spectroscopy in patients with traumatic brain injury, taking into account the advantages and the disadvantages of this technique.
\end{abstract}

Keywords: cerebral oximetry; near-infrared spectroscopy; traumatic brain injury; cerebrovascular autoregulation; intracranial pressure

\section{Introduction}

Traumatic brain injuries (TBIs) are some of the main causes of mortality in patients injured as a result of traffic accidents, falls from a height, battery, or firearm assault. TBIs are classified in various ways. Depending on the severity of the injury, they are divided into mild, moderate, and severe injuries. Depending on the mechanism of injury, they are classified into focal injuries and primary diffuse brain injuries. They can be isolated or part of a multi-organ trauma. TBI leads to primary brain injury.

Treatment of patients with TBI is primarily focused on preventing secondary brain injury. For many years, the standard of care for patients with TBI has been the monitoring of intracranial pressure (ICP) and cerebral perfusion pressure (CPP), estimated as the difference between ICP and mean arterial pressure (MAP) [1]. Continuous EEG monitoring is also increasingly used. However, these methods do not provide direct information on hypoxia and ischemia or the metabolic needs of the brain tissue. Hence, there is a need to use a method that would allow the assessment of cerebral oxygenation.

For almost 30 years now, a method of non-invasive monitoring of cerebral oximetry using near-infrared spectroscopy (NIRS) has been available. This technique was initially used in neonatal intensive care [2] and cardiac surgery [3], and has since been increasingly employed in adult intensive care. 


\section{Near-Infrared Spectroscopy (NIRS)}

Cerebral oximetry measurements are performed using near-infrared spectroscopy (NIRS). It is a continuous, non-invasive method that enables monitoring of regional cerebral oxygen saturation. Normal NIRS readings represent a balance between oxygen supply and consumption in peripheral tissues.

The technique was first described by Jobsis in 1977 [4]. Under physiological conditions, tissues are relatively translucent to near-infrared light with wavelengths of 700-1000 nm, and the absorption of light by tissues is low. As a result, light can penetrate to a depth of up to $8 \mathrm{~cm}$ and still be completely detectable. [5]. Near-infrared light beams can penetrate bones, which is essential for transcranial monitoring of cerebral oximetry.

Cerebral oximetry measurements are cheap and easy to take. Special sensors are applied to the scalp which allow one to obtain measurements mainly from the external parts of the brain. For practical reasons, the sensors are commonly attached to the scalp overlying the frontal lobe, but measurements can be made from above any brain lobe. Each probe has a near-infrared light generator (diode or laser) and a proximal and distal light detector. Mixed arterial and venous blood in the brain and external tissues is measured. The arterial to venous blood ratio in the brain is 15:85 [6]. Hemoglobin oxygenation in brain vessels is estimated using percutaneous measurements of the amount of light absorbed by hemoglobin in the cerebral cortex.

The light transmitted through biological tissues is reflected, absorbed and scattered. Light reflection is determined by the angle between the light beam and the tissue surface. The absorption of light by tissues, causing the attenuation of light, depends on the chromophores-oxyhemoglobin, deoxyhaemoglobin and cytochrome oxidase. NIRS uses the different absorption properties of oxyhemoglobin, deoxyhaemoglobin and cytochrome oxidase to quantify their concentrations in tissues [7]. The relationship between the concentration of chromophore $(c)$, its extinction coefficient $(\alpha)$, distance traveled by light in tissues $(d)$, and the ratio of the incident light intensity $\left(I_{0}\right)$ to the intensity of transmitted light $(I)$ is determined by the Beer-Lambert equation $[5,8]$ :

$$
A=\log \left(I_{0} / I\right)=\alpha \times c \times d
$$

Most photons in tissues are scattered, so the path traveled by photons can be much longer than the direct distance between the optodes. Most of the total attenuation of an infrared light beam is due to scattering, and only a small portion is absorbed. That is why the differential pathlength factor (DPF) and factor G, which depends on light losses other than attenuation, need to be added to the above equation [5,9]:

$$
A=\log \left(I_{0} / I\right)=\alpha \times c \times d \times D P F+G
$$

NIRS measurements in adults can be performed with the emitter and detectors placed on the same side of the head, providing "regional" information on brain oxygenation as only a small volume of brain tissue between the optodes is examined. In this method, the light travels along an arc with a tissue penetration depth of approximately half the distance between the emitter and the detectors. It is recommended that the distance between the optodes be not less than 2.5 to $3 \mathrm{~cm}$, because the shorter the distance between the optodes, the more strongly the extracerebral tissues attenuate the light [5].

The first NIRS devices used two or three wavelengths and were mainly trend monitors. Nowadays, a four-wavelength generation of NIRS monitors are available, which provide reliable real-time regional cerebral oxygen saturation readings. NIRS devices can use three different detection modes: continuous wave (CW), frequency domain (FD), and time domain (TD). CW monitors are the most popular and the simplest devices. They measure the attenuation of incident light. FD monitors use high-frequency modulation to measure the phase and intensity of the signals generated. This technique allows a more quantitative assessment of the optical properties of tissues. TD monitors measure the time of flight of photons and are the most expensive of all NIRS devices [10]. 


\section{Usefulness of Monitoring Cerebral Oximetry in TBI Patients by NIRS \\ 3.1. Identification of Episodes of Impaired Cerebral Oxygenation}

Adequate cerebral oxygenation is essential in treating patients with TBI. There exist invasive measurement methods, such as the measurement of jugular bulb oxygen saturation (SjvO2) or the measurement of brain tissue oxygen pressure (PbtO2). However, cerebral oximeters using NIRS are more and more frequently employed to obtain non-invasive measurements of cerebral oxygenation.

In a study by Esnault et al., cerebral oximetry $(\mathrm{rScO} 2)$ values obtained by NIRS were compared with the results of an invasive measurement of brain tissue oxygen pressure. $\mathrm{A} \mathrm{PbtO} 2$ probe was inserted into the frontal lobe of the cerebral hemisphere with more severe tissue injury/damage. The $\mathrm{rScO} 2$ sensor, on the other hand, was placed on the skin in the frontal area ipsilateral to the $\mathrm{PbtO} 2$ probe. The authors found no correlation between the readings obtained with NIRS and the tissue oxygen pressure probe. Cerebral oximetry allowed one to identify only about $15 \%$ of the ischemic episodes detected by the $\mathrm{PbtO} 2$ measurement. When one of the subjects developed brain death, NIRS continued to show normal $\mathrm{rScO} 2$ values, while $\mathrm{PbtO} 2$ dropped to $0 \mathrm{mmHg}$. Esnault et al. concluded that $\mathrm{rScO} 2$ measurement could not be used interchangeably with $\mathrm{PbtO} 2$ as a monitor of cerebral oxygenation in patients with TBI [11].

The correlation between $\mathrm{rScO} 2$ and $\mathrm{PbtO} 2$ in TBI patients was also investigated by Leal-Noval et al. In their study, involving 56 patients, a weak correlation was observed between $\mathrm{rScO} 2$ and $\mathrm{PbtO} 2$ measurements. Moreover, $\mathrm{rScO} 2$ was shown to have poor accuracy in detecting moderate cerebral hypoxia [12], which is in agreement with the observations made by Esnault et al. [11]. Detectability improved when hypoxia reached $\mathrm{PbtO} 2$ values $<12 \mathrm{mmHg}$ [12].

Entirely different observations have been reported by Brawanski et al. Over $90 \%$ of their $\mathrm{rScO} 2$ readings from the frontal area and $\mathrm{PbtO} 2$ measurements from the white matter of the frontal lobe showed a significant correlation. An analysis of their data indicated that the $\mathrm{PbrO} 2$ and the $\mathrm{rScO} 2$ signals contained similar information despite the fact that they were obtained using completely different technologies [13]. A significant correlation between $\mathrm{PbtO} 2$ and $\mathrm{rScO} 2$ readings has also been demonstrated in patients with TBI in other research [14].

In a study comparing two types of NIRS monitors-NIRO 200, which measures the cerebral tissue oxygenation index (TOI), and INVOS 5100, which monitors $\mathrm{rScO} 2$, jugular bulb oxygen saturation $(\mathrm{SjvO} 2)$ and central venous saturation $(\mathrm{ScvO} 2)$ were also measured. Thirty one pediatric patients with congenital heart defects were examined. A significant correlation was demonstrated between the $\mathrm{rScO} 2$ and $\mathrm{SjvO} 2$ measurements, and an even higher correlation between $\mathrm{rScO} 2$ and $\mathrm{ScvO} 2$. Similarly, a high correlation between readings was observed for TOI [15].

Monitoring of cerebral oximetry using NIRS in septic shock patients allowed investigation of the relationship between $\mathrm{rScO} 2$ and $\mathrm{ScvO} 2 . \mathrm{rScO} 2$ and $\mathrm{ScvO} 2$ values increased with the progressing stabilization of the patients' condition and the decrease in lactic acidosis. The study demonstrated that there was a significant negative correlation between lactic acid levels and $\mathrm{rScO} 2$ values. On the other hand, a significant positive correlation between $\mathrm{rScO} 2$ and $\mathrm{ScvO} 2$ readings was observed at $8,24,48$, and $72 \mathrm{~h}$ after admission to the ICU [16].

Many authors believe that cerebral oximetry monitoring using NIRS is an unreliable technique for monitoring oxygen metabolism in the brain tissue compared to measurements of brain tissue oxygen pressure. However, it should be noted that $\mathrm{rScO} 2$ and $\mathrm{PbtO} 2$ measure different parameters using different techniques. Moreover, $\mathrm{PbtO} 2$ is not acknowledged as a gold standard for monitoring oxygen metabolism in the brain. $\mathrm{PbtO} 2$ measurements are representative of a small area of tissue in the immediate vicinity of the probe. On the other hand, monitoring of $\mathrm{rScO} 2$ could prove very useful in patients in whom an invasive technique cannot or should not be used for various reasons. Both of these parameters could be monitored simultaneously to obtain a more complete picture of changes in cerebral 
oxygen metabolism [17]. Of note, jugular bulb oxygen saturation measurement, commonly used in TBI patients, gives a more global picture of cerebral oxygenation, and so local tissue hypoxia may go unnoticed when using this technique [18].

\subsection{Monitoring of Cerebrovascular Autoregulation}

Autoregulation of cerebral blood flow (CBF) is one of the most important mechanisms for maintaining intracranial homeostasis. It keeps $\mathrm{CBF}$ at a constant level in the face of changing cerebral perfusion pressure (CPP). This prevents disturbances in $\mathrm{CBF}$ during significant changes in arterial blood pressure. Autoregulation is extremely important in TBI patients in the context of the development of secondary injuries. As a result of impaired autoregulation, the balance between the cerebral metabolic rate of oxygen (CMRO2), cerebral blood volume (CBV) and CBF can be disturbed. This may lead to ischemic or hyperemic brain lesions, hypoxia or increased intracranial pressure. There is ample scientific evidence that abnormal autoregulation of $\mathrm{CBF}$ is associated with poorer treatment outcomes in patients with TBI $[19,20]$. Monitoring of CBF autoregulation may allow to individualize CPP targets in patients with TBI, which is associated with improved treatment outcomes [21,22].

Currently, different methods are available for assessing CBF autoregulation. The most widely used invasive techniques include measurement of intracranial pressure (ICP) and direct measurement of oxygen content in the brain tissue (parenchymal $\mathrm{PbtO} 2$ monitoring). Among non-invasive methods, transcranial Doppler (TCD) ultrasonography, which measures CBF velocity [23], and NIRS cerebral oximetry are commonly employed.

The values of cerebral oximetry are mainly influenced by CBF, cerebral metabolic rate of oxygen and arterial blood oxygen content. Owing to the fact that the factors affecting oxygen metabolism are relatively stable over short periods of time, NIRS can be used in place of invasive methods of bedside monitoring of changes in CBF [24,25].

Depending on the manufacturer and the technology used, NIRS devices generate various measurements, such as regional cerebral oxygen saturation $(\mathrm{rScO} 2)$, cerebral blood flow index $(\mathrm{rCBFi})$, tissue oxygenation index (TOI), and relative total tissue hemoglobin concentration $(\mathrm{rTHb})[26]$.

Analyses of cerebrovascular autoregulation include computing correlations of CBF or CBV with CPP using mathematical models (e.g., COx for rScO2 or TOx for TOI) [27]. Brady et al. monitored cerebral autoregulation with a NIRS monitor in piglets using the cerebral oximetry index (COx) as an indicator of autoregulatory vascular reactivity. By correlating $\mathrm{rScO} 2$ values measured using NIRS with mean arterial pressure (MAP) readings, one can calculate $\mathrm{COx}$. If $\mathrm{COx}$ is close to zero, there is no correlation between $\mathrm{rScO} 2$ and MAP because blood pressure is in the autoregulation range. On the other hand, COx values close to one, point to a strong correlation between cerebral oximetry and MAP, which is interpreted as impaired CBF autoregulation or as a MAP beyond the limit of autoregulation [25]. In Brady et al.'s study, COx values were compared with invasive measurements using the laser-Doppler index (LDx). Those authors demonstrated that COx displayed high sensitivity and specificity in detecting cerebrovascular autoregulation disorders caused by hypotension in piglets. The COx readings correlated with those obtained using LDx. Brady et al. showed that COx was sensitive to the loss of cerebrovascular autoregulation and could be a valuable non-invasive method for continuous monitoring of autoregulation in patients with TBI.

Monitoring of CBF autoregulation using NIRS has also been studied in patients with sepsis. NIRS readings were consistent with measurements of changes in autoregulation performed using TCD [27]. Similar results, showing the compatibility of NIRS with TCD measurements, were obtained by Zheng et al. [28].

Currently, the market offers a CBF monitoring device called c-FLOW Ornim Medical LTD device, which uses low-power ultrasound and near-infrared laser light to continuously monitor blood flow in tissue microcirculation. It tracks CBF trends, continuously measures blood pressure, and correlates the measurements to provide a real-time autoregulation 
index. This allows to identify the limits of cerebrovascular autoregulation and detect impairments in autoregulation [29].

\subsection{Monitoring of Cerebral Blood Flow}

In a study of non-invasive CBF measurement using NIRS and indocyanine green, Gora et al. obtained CBF values that were low compared to those obtained with conventional positron emission tomography (PET) [30]. Similarly, NIRS measurements of CBV yielded low results, which appeared to be related to contamination of the path near-infrared light travels from the emitter to the detector by extracerebral tissues. It is difficult to assess the volume and density of these tissues and their optical properties [31]. It seems that in order for NIRS to be used for the measurement of CBF and CBV in clinical settings, the contribution of extracerebral signals to NIRS readings must be further investigated [30]. Also, the influence of indocyanine green on the values of cerebral oximetry measured with NIRS does not seem to be entirely clear. Yoo et al. obtained falsely elevated cerebral oximetry readings after an intravenous bolus of indocyanine green. This marker mainly absorbs light in the near-infrared range of $600-900 \mathrm{~nm}$. Therefore, one should expect that, similarly to indigo carmine or methylene blue, the use of indocyanine green would dampen cerebral oximetry readings. In Yoo et al.'s study, a several-minute increase in $\mathrm{rScO} 2$ co-occurred with a significantly shorter-lasting decrease in blood saturation (SpO2). The authors lean towards the theory that indocyanine green reduces the amount of light detected by NIRS devices at a wavelength of $810 \mathrm{~nm}$, which is interpreted as an increase in the concentration of oxyhemoglobin and results in falsely elevated cerebral oximetry readings [32].

In contrast to these observations are the results of a study by Keller et al., in which measurements obtained by NIRS and indocyanine green were consistent with those obtained by MRI [33]. Also in the study by Milej et al. a significant correlation of the CBF values obtained with the NIRS and indocyanine green was demonstrated with the CBF measurements obtained by MRI [34].

\subsection{Detection of Increased Intracranial Pressure}

In patients with TBI, monitoring of ICP is extremely important in preventing secondary injuries. An increase in ICP is associated with a decrease in CPP, and thus a decline in CBF, which can lead, among others, to a secondary ischemic phenomenon. Moreover, elevated ICP values in patients with TBI are associated with a higher risk of death [35].

Typically, ICP is measured invasively using a probe placed inside the brain. However, attempts are being made at using NIRS cerebral oximetry measurements as a non-invasive ICP monitor.

Kampfl et al. used NIRS to monitor cerebral oximetry in two groups of patients with TBI-with ICP higher or lower than $25 \mathrm{mmHg}$. They observed significantly lower values of $\mathrm{rScO} 2$ in patients with increased ICP compared to the group of patients with ICP below $25 \mathrm{mmHg}$. Moreover, no differences were observed between CPP, TCD or blood gas values between these two groups. It seems that cerebral oximetry monitoring using NIRS may be of help in detecting CBF abnormalities in patients with elevated ICP [36].

Similar observations were made by Dias et al. in a study of the characteristics of plateau waves of intracranial pressure. They observed that an increase in ICP was associated with the detection of brain hypoxia by NIRS [37].

By contrast, Zuluaga et al. observed different trends in $\mathrm{rScO} 2$ in a pediatric population depending on the underlying disease causing intracranial hypertension. $\mathrm{rScO} 2$ decreased with increasing ICP in children with brain tumors and hydrocephalus, but increased when ICP was caused by intracranial hemorrhage. The authors clearly demonstrated that changes in $\mathrm{rScO} 2$ were not significantly related to CPP or ICP. Accordingly, NIRS does not seem to be an appropriate method for monitoring and predicting changes in ICP [38].

It should be noted that in all the studies reviewed here, authors observed changes in cerebral oximetry readings in response to an increase in ICP, thus confirming the usefulness of NIRS in detecting hypoxic episodes. However, these studies do not confirm that NIRS 
allows to directly diagnose changes in ICP. Nonetheless, it seems that monitoring of $\mathrm{rScO} 2$ in patients with TBI may be used as an auxiliary method to signal a possible increase in ICP and the need to initiate more invasive monitoring.

\subsection{NIRS and Diffuse Correlation Spectroscopy}

A newer method of monitoring CBF that uses infrared light is diffuse correlation spectroscopy (DCS), which is based on the use of the intensity fluctuations of near-infrared light.

In a study carried out on neonatal piglets with closed head injury simulating TBI, CBF was monitored with DCS and cerebral blood oxygenation using NIRS. A significant correlation of the results obtained with the DCS with the values obtained with the fluorescent microsphere technique was demonstrated. Measurements made with DCS correlated with the values of arterial oxygen saturation, mean arterial pressure and heart rate. DCS was also sensitive to changing physiological conditions such as cardiac arrest [39].

Baker et al. monitored CBF and oxidative metabolism in brain-injured adults. In the research, they used both invasive methods such as ICP monitor or cerebral microdialysis, as well as non-invasive measurement of NIRS and DCS. Conducted observations confirmed the usefulness of non-invasive methods in monitoring patients with brain injury. There were no significant correlations between the absolute values of the parameters measured with invasive and non-invasive methods. However, the NIRS and DCS measurements allowed the detection of disproportions between cerebral perfusion and oxygen metabolism during specific clinical events, which were also observed by invasive methods. The possibility of longitudinal assessment of cerebral autoregulation, based on non-invasive measurements, has also been demonstrated [40].

Due to the use of hybrid monitors, using both the NIRS and DCS techniques, it is also possible to estimate $\mathrm{CMRO} 2$ [41]. The combination of both monitoring techniques has also been successfully used in studies among patients undergoing elective cardiac surgery with use of circulatory arrest by measuring cerebral oximetry, CBF and CMRO2. DCS allows the identification of periods of brain hyperperfusion and hypoperfusion during circulatory arrest [42].

\section{Limitations of the Use of Cerebral Oximetry Measurements with NIRS}

Although monitoring of cerebral oximetry using NIRS has been refined over the years, it still has some limitations.

An unquestionable disadvantage of this monitoring technique is the multitude of devices available on the market, which differ in the technical aspects of making measurements, and therefore cannot be used interchangeably [43].

The results obtained with the use of NIRS are influenced by extracerebral blood flow, cerebrospinal fluid, thickness of skull bones, and myelin sheaths [44]. Interference from the lighting used in the room in which oximetry is performed, which is often overlooked in practice, is important as well. Oximetry readings can also be affected by skin pigmentation. Another problem is the falsification of measurements by myoglobin, as hemoglobin and myoglobin have similar optical properties. This may cause an overestimation of hemoglobin saturation readings [45]. Hirasawa et al. demonstrated that extracranial blood flow had an effect on cerebral oximetry readings regardless of the distance between the emitter and the detector [46].

The range of normal cerebral oximetry values is also still being discussed. The most commonly used lower and upper limits are $60 \%$ and $75 \%$, respectively, with deviations from these baseline values as high as $10 \%$. These limits are individually variable and depend on comorbidities [47].

In patients with TBI, there are also other issues. These patients very often have multiple wounds or postoperative sutures on the scalp, as well as subcutaneous hematomas accompanied by swelling of the soft tissues. These lesions make it impossible to properly attach NIRS electrodes, or cause disturbances in signal reception and falsify readings. 
The influence of the presence of hematomas and brain edema on the absorption and scattering of near-infrared light in TBI patients has also been debated [48].

Importantly, there have been reports of measuring devices registering normal cerebral oximetry values in patients with confirmed absence of cerebral perfusion [49]. These reports seem to call into question all the other observations and the knowledge gained from them.

\section{Conclusions}

Cerebral oximetry monitoring using NIRS is increasingly employed in the therapy of TBI patients, not only to register cerebral oximetry. The greatest advantage of this method is that it enables continuous and non-invasive measurement of $\mathrm{rScO} 2$. Despite technical imperfections, cerebral oximetry measurements can be an important complement to other parameters monitored, providing a more holistic picture of intracranial pathologies. However, attention should be paid to the still present technical imperfections of the method, which significantly affect the obtained, often inconclusive results.

Author Contributions: Conceptualization, M.B. (Małgorzata Barud) and W.D.; methodology, M.B. (Małgorzata Barud); formal analysis, M.B. (Małgorzata Barud), W.D.; writing-original draft preparation, M.B. (Małgorzata Barud), W.D., D.S.-G.; writing-review and editing, M.B. (Małgorzata Barud), W.D., D.S.-G., C.R., M.B. (Magdalena Bielacz), R.B.; visualization, M.B. (Małgorzata Barud), W.D., D. S-G., C.R., M.B. (Magdalena Bielacz), R.B.; supervision, M.B. (Małgorzata Barud), W.D., D.S-G., C.R., M.B. (Magdalena Bielacz), R.B.; project administration, M.B. (Małgorzata Barud), W.D., D.S.-G., C.R., M.B. (Magdalena Bielacz), R.B. All authors have read and agreed to the published version of the manuscript.

Funding: This manuscript received no external funding.

Institutional Review Board Statement: Not applicable.

Informed Consent Statement: Not applicable.

Data Availability Statement: Not applicable.

Conflicts of Interest: The authors declare no conflict of interest.

\section{References}

1. Carney, N.; Totten, A.M.; O’Reilly, C.; Ullman, J.S.; Hawryluk, G.W.; Bell, M.J.; Bratton, S.L.; Chesnut, R.; Harris, O.A.; Kissoon, N.; et al. Guidelines for the Management of Severe Traumatic Brain Injury, Fourth Edition. Neurosurgery 2017, 80, 6-15. [CrossRef]

2. Brazy, J.E.; Lewis, D.V.; Mitnick, M.H.; Jöbsis vander Vliet, F.F. Noninvasive monitoring of cerebral oxygenation in preterm infants: Preliminary observations. Pediatrics 1985, 75, 217-225. [PubMed]

3. Murkin, J.M.; Adams, S.J.; Novick, R.J.; Quantz, M.; Bainbridge, D.; Iglesias, I.; Cleland, A.; Schaefer, B.; Irwin, B.; Fox, S. Monitoring brain oxygen saturation during coronary bypass surgery: A randomized, prospective study. Anesth. Analg. 2007, 104, 51-58. [CrossRef] [PubMed]

4. Jobsis, F.F. Noninvasive infrared monitoring of cerebral and myocardial oxygen sufficiency and circulatory parameters. Science 1977, 23, 1264-1267. [CrossRef] [PubMed]

5. Pellicer, A.; Bravo, M.C. Near-infrared spectroscopy: A methodology-focused review. Semin. Fetal Neonatal Med. 2011, 16, 42-49. [CrossRef]

6. Casati, A.; Spreafico, E.; Putzu, M.; Fanelli, G. New technology for noninvasive brain monitoring: Continuous cerebral oximetry. Minerva Anestesiol. 2006, 72, 605-625. [PubMed]

7. Murkin, J.M.; Arango, M. Near-infrared spectroscopy as an index of brain and tissue oxygenation. Br. J. Anaesth. 2009, 103, i3-i13. [CrossRef]

8. Owen-Reece, H.; Smith, M.; Elwell, C.E.; Goldstone, J.C. Near infrared spectroscopy. Br. J. Anaesth. 1999, 82, 418-444. [CrossRef]

9. Madsen, P.L.; Secher, N.H. Near-infrared oximetry of the brain. Prog. Neurobiol. 1999, 58, 541-560. [CrossRef]

10. Davies, D.J.; Su, Z.; Clancy, M.T.; Lucas, S.J.E.; Dehghani, H.; Logan, A.; Belli, A. Near-Infrared Spectroscopy in the Monitoring of Adult Traumatic Brain Injury: A Review. J. Neurotrauma 2015, 32, 933-941. [CrossRef]

11. Esnault, P.; Boret, H.; Montcriol, A.; Carre, E.; Prunet, B.; Bordes, J.; Simon, P.; Joubert, C.; Dagain, A.; Kaiser, E.; et al. Assessment of cerebral oxygenation in neurocritical care patients: Comparison of a new four wavelengths forehead regional saturation in oxygen sensor (EQUANOX ${ }^{\circledR}$ ) with brain tissue oxygenation. A prospective observational study. Minerva Anestesiol. 2015, $81,876-884$. 
12. Leal-Noval, S.R.; Cayuela, A.; Arellano-Orden, V.; Marín-Caballos, A.; Padilla, V.; Ferrándiz-Millón, C.; Corcia, Y.; García-Alfaro, C.; Amaya-Villar, R.; Murillo-Cabezas, F. Invasive and noninvasive assessment of cerebral oxygenation in patients with severe traumatic brain injury. Intensive Care Med. 2010, 36, 1309-1317. [CrossRef]

13. Brawanski, A.; Faltermeier, R.; Rothoerl, R.D.; Woertgen, C. Comparison of near-infrared spectroscopy and tissue $\mathrm{P}(\mathrm{O} 2)$ time series in patients after severe head injury and aneurysmal subarachnoid hemorrhage. J. Cereb. Blood Flow Metab. 2002, 22, 605-611. [CrossRef]

14. Holzschuh, M.; Woertgen, C.; Metz, C.; Brawanski, A. Dynamic changes of cerebral oxygenation measured by brain tissue oxygen pressure and near infrared spectroscopy. Neurol. Res. 1997, 19, 246-248. [CrossRef]

15. Nagdyman, N.; Ewert, P.; Peters, B.; Miera, O.; Fleck, T.; Berger, F. Comparison of different near-infrared spectroscopic cerebral oxygenation indices with central venous and jugular venous oxygenation saturation in children. Paediatr. Anaesth. 2008, 18, 160-166. [CrossRef]

16. Al Tayar, A.; Abouelela, A.; Mohiuddeen, K. Can the cerebral regional oxygen saturation be a perfusion parameter in shock? J. Crit. Care 2017, 38, 164-167. [CrossRef]

17. Forcione, M.; Ganau, M.; Prisco, L.; Chiarelli, A.M.; Bellelli, A.; Belli, A.; Davies, D.J. Mismatch between Tissue Partial Oxygen Pressure and Near-Infrared Spectroscopy Neuromonitoring of Tissue Respiration in Acute Brain Trauma: The Rationale for Implementing a Multimodal Monitoring Strategy. Int. J. Mol. Sci. 2021, 22, 1122. [CrossRef] [PubMed]

18. Gupta, A.K.; Hutchinson, P.J.; Al-Rawi, P.; Gupta, S.; Swart, M.; Kirkpatrick, P.J.; Menon, D.K.; Datta, A.K. Measuring brain tissue oxygenation compared with jugular venous oxygen saturation for monitoring cerebral oxygenation after traumatic brain injury. Anesth. Analg. 1999, 88, 549-553. [CrossRef] [PubMed]

19. Lam, J.M.; Hsiang, J.N.; Poon, W.S. Monitoring of autoregulation using laser Doppler flowmetry in patients with head injury. J. Neurosurg. 1997, 86, 438-445. [CrossRef] [PubMed]

20. Rivera-Lara, L.; Zorrilla-Vaca, A.; Geocadin, R.G.; Healy, R.J.; Ziai, W.; Mirski, M.A. Cerebral Autoregulation-oriented Therapy at the Bedside: A Comprehensive Review. Anesthesiology 2017, 126, 1187-1199. [CrossRef] [PubMed]

21. Budohoski, K.P.; Czosnyka, M.; Smielewski, P.; Varsos, G.V.; Kasprowicz, M.; Brady, K.M.; Pickard, J.D.; Kirkpatrick, P.J. Cerebral autoregulation after subarachnoid hemorrhage: Comparison of three methods. J. Cereb. Blood Flow Metab. 2013, 33, 449-456. [CrossRef]

22. Aries, M.J.; Czosnyka, M.; Budohoski, K.P.; Steiner, L.A.; Lavinio, A.; Kolias, A.G.; Hutchinson, P.J.; Brady, K.M.; Menon, D.K.; Pickard, J.D.; et al. Continuous determination of optimal cerebral perfusion pressure in traumatic brain injury. Crit. Care Med. 2012, 40, 2456-2463. [CrossRef]

23. Joshi, B.; Ono, M.; Brown, C.; Brady, K.; Easley, R.B.; Yenokyan, G.; Gottesman, R.F.; Hogue, C.W. Predicting the limits of cerebral autoregulation during cardiopulmonary bypass. Anesth. Analg. 2012, 114, 503-510. [CrossRef]

24. Smielewski, P.; Kirkpatrick, P.; Minhas, P.; Pickard, J.D.; Czosnyka, M. Can cerebrovascular reactivity be measured with near-infrared spectroscopy? Stroke 1995, 26, 2285-2292. [CrossRef] [PubMed]

25. Brady, K.M.; Lee, J.K.; Kibler, K.K.; Smielewski, P.; Czosnyka, M.; Easley, R.B.; Koehler, R.C.; Shaffner, D.H. Continuous time-domain analysis of cerebrovascular autoregulation using near-infrared spectroscopy. Stroke 2007, 38, 2818-2825. [CrossRef]

26. Bush, B.; Sam, K.; Rosenblatt, K. The Role of Near-infrared Spectroscopy in Cerebral Autoregulation Monitoring. J. Neurosurg. Anesthesiol. 2019, 31, 269-270. [CrossRef]

27. Steiner, L.A.; Pfister, D.; Strebel, S.P.; Radolovich, D.; Smielewski, P.; Czosnyka, M. Near-infrared spectroscopy can monitor dynamic cerebral autoregulation in adults. Neurocrit. Care 2009, 10, 122-128. [CrossRef]

28. Zheng, Y.; Villamayor, A.J.; Merritt, W.; Pustavoitau, A.; Latif, A.; Bhambhani, R.; Frank, S.; Gurakar, A.; Singer, A.; Cameron, A.; et al. Continuous cerebral blood flow autoregulation monitoring in patients undergoing liver transplantation. Neurocrit. Care 2012, 17, 77-84. [CrossRef] [PubMed]

29. Tsalach, A.; Ratner, E.; Lokshin, S.; Silman, Z.; Breskin, I.; Budin, N.; Kamar, M. Cerebral Autoregulation Real-Time Monitoring. PLOS ONE 2016, 11, e0161907. [CrossRef]

30. Gora, F.; Shinde, S.; Elwell, C.E.; Goldstone, J.C.; Cope, M.; Delpy, D.T.; Smith, M. Noninvasive measurement of cerebral blood flow in adults using near-infrared spectroscopy and indocyanine green: A pilot study. J. Neurosurg. Anesthesiol. 2002, 14, 218-222. [CrossRef]

31. Hopton, P.; Walsh, T.S.; Lee, A. Measurement of cerebral blood volume using near-infrared spectroscopy and indocyanine green elimination. J. Appl. Physiol. 1999, 87, 1981-1987. [CrossRef]

32. Yoo, K.Y.; Baek, H.Y.; Jeong, S.; Hallacoglu, B.; Lee, J. Intravenously administered indocyanine green may cause falsely high near-infrared cerebral oximetry readings. J. Neurosurg. Anesthesiol. 2015, 27, 57-60. [CrossRef]

33. Keller, E.; Nadler, A.; Alkadhi, H.; Kollias, S.S.; Yonekawa, Y.; Niederer, P. Noninvasive measurement of regional cerebral blood flow and regional cerebral blood volume by near-infrared spectroscopy and indocyanine green dye dilution. NeuroImage 2003, 20, 828-839. [CrossRef]

34. Milej, D.; He, L.; Abdalmalak, A.; Baker, W.B.; Anazodo, U.C.; Diop, M.; Dolui, S.; Kavuri, V.C.; Pavlosky, W.; Wang, L.; et al. Quantification of cerebral blood flow in adults by contrast-enhanced near-infrared spectroscopy: Validation against MRI. J. Cereb. Blood Flow Metab. 2020, 40, 1672-1684. [CrossRef] [PubMed]

35. Balestreri, M.; Czosnyka, M.; Hutchinson, P.; Steiner, L.A.; Hiler, M.; Smielewski, P.; Pickard, J.D. Impact of intracranial pressure and cerebral perfusion pressure on severe disability and mortality after head injury. Neurocrit. Care 2006, 4, 8-13. [CrossRef] 
36. Kampfl, A.; Pfausler, B.; Denchev, D.; Jaring, H.P.; Schmutzhard, E. Near infrared spectroscopy (NIRS) in patients with severe brain injury and elevated intracranial pressure. A pilot study. Acta Neurochir. Suppl. 1997, 70, 112-114. [CrossRef]

37. Dias, C.; Maia, I.; Cerejo, A.; Smielewski, P.; Paiva, J.A.; Czosnyka, M. Plateau Waves of Intracranial Pressure and Multimodal Brain Monitoring. Acta Neurochir. Suppl. 2016, 122, 143-146. [CrossRef]

38. Zuluaga, M.T.; Esch, M.E.; Cvijanovich, N.Z.; Gupta, N.; McQuillen, P.S. Diagnosis influences response of cerebral near infrared spectroscopy to intracranial hypertension in children. Pediatr. Crit. Care Med. 2010, 11, 514-522. [CrossRef] [PubMed]

39. Zhou, C.; Eucker, S.A.; Durduran, T.; Yu, G.; Ralston, J.; Friess, S.H.; Ichord, R.N.; Margulies, S.S.; Yodh, A.G. Diffuse optical monitoring of hemodynamic changes in piglet brain with closed head injury. J. Biomed. Opt. 2009, 14, e034015. [CrossRef]

40. Baker, W.B.; Balu, R.; He, L.; Kavuri, V.C.; Busch, D.R.; Amendolia, O.; Francis Quattrone, F.; Suzanne Frangos, S.; MaloneyWilensky, E.; Abramson, K.; et al. Continuous non-invasive optical monitoring of cerebral blood flow and oxidative metabolism after acute brain injury. J. Cereb. Blood Flow Metab. 2019, 39, 1469-1485. [CrossRef] [PubMed]

41. Boas, D.A.; Franceschini, M.A. Haemoglobin oxygen saturation as a biomarker: The problem and a solution. Philos. Trans. A Math. Phys. Eng. Sci. 2011, 369, 4407-4424. [CrossRef]

42. Zavriyev, A.I.; Kaya, K.; Farzam, P.; Farzam, P.Y.; Sunwoo, J.; Jassar, A.S.; Sundt, T.M.; Carp, S.A.; Franceschini, M.A.; Qu, J.Z. The role of diffuse correlation spectroscopy and frequency-domain near-infrared spectroscopy in monitoring cerebral hemodynamics during hypothermic circulatory arrests. JTCVS Tech. 2021, 7, 161-177. [CrossRef]

43. Fellahi, J.L.; Butin, G.; Fischer, M.O.; Zamparini, G.; Gérard, J.L.; Hanouz, J.L. Dynamic evaluation of near-infrared peripheral oximetry in healthy volunteers: A comparison between INVOS and EQUANOX. J. Crit. Care 2013, 28, 881. [CrossRef]

44. Yoshitani, K.; Kawaguchi, M.; Miura, N.; Okuno, T.; Kanoda, T.; Ohnishi, Y.; Kuro, M. Effects of hemoglobin concentration, skull thickness, and the area of the cerebrospinal fluid layer on near-infrared spectroscopy measurements. Anesthesiology 2007, 106, 458-462. [CrossRef] [PubMed]

45. Scheeren, T.W.; Schober, P.; Schwarte, L.A. Monitoring tissue oxygenation by near infrared spectroscopy (NIRS): Background and current applications. J. Clin. Monit. Comput. 2012, 26, 279-287. [CrossRef]

46. Hirasawa, A.; Yanagisawa, S.; Tanaka, N.; Funane, T.; Kiguchi, M.; Sørensen, H.; Secher, N.H.; Ogoh, S. Influence of skin blood flow and source-detector distance on near-infrared spectroscopy-determined cerebral oxygenation in humans. Clin. Physiol. Funct. Imaging 2015, 35, 237-244. [CrossRef] [PubMed]

47. Thavasothy, M.; Broadhead, M.; Elwell, C.; Peters, M.; Smith, M. A comparison of cerebral oxygenation as measured by the NIRO 300 and the INVOS 5100 Near-Infrared Spectrophotometers. Anaesthesia 2002, 57, 999-1006. [CrossRef]

48. Calderon-Arnulphi, M.; Alaraj, A.; Slavin, K.V. Near infrared technology in neuroscience: Past, present and future. Neurol. Res. 2009, 31, 605-614. [CrossRef]

49. Gomersall, C.D.; Joynt, G.M.; Gin, T.; Freebairn, R.C.; Stewart, I.E. Failure of the INVOS 3100 cerebral oximeter to detect complete absence of cerebral blood flow. Crit. Care Med. 1997, 25, 1252-1254. [CrossRef] 